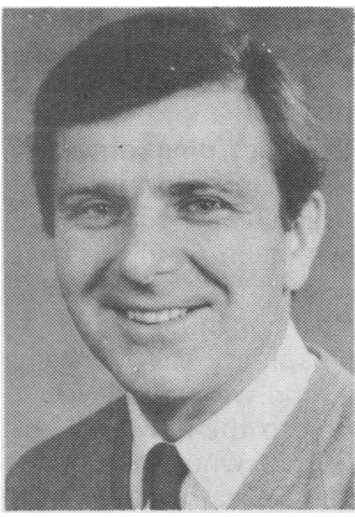

C. Williams

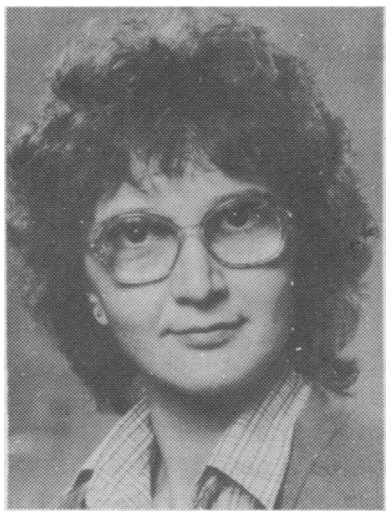

Maria L. G. Nute

\title{
SOME PHYSIOLOGICAL DEMANDS OF A HALF-MARATHON RACE ON RECREATIONAL RUNNERS
}

\author{
C. WILLIAMS, BSc, MSc, PhD and Maria L. G. NUTE, BSc
}

Department of Physical Education and Sports Science, University of Technology, Loughborough, Leics. LE11 $3 T U$

\begin{abstract}
The purpose of this study was to assess the physiological demands of a half-marathon race on a group of ten recreational runners (8 men and 2 women). The average running speed was $223.1 \pm 22.7 \mathrm{~m} \cdot \mathrm{min}^{-1}$ (mean \pm SD) for the group and this represented $79 \pm 5 \% \mathrm{VO}_{2} \max$ for these runners. There was a good correlation between $\mathrm{VO}_{2} \max$ and performance time for the race $(r=-0.81 ; p<0.01)$ and an even better correlation between running speed equivalent to a blood lactate concentration of 4 mmol. $\Gamma^{1}$ and performance times $(r=-0.877 ; p<0.01)$. The blood lactate concentration of 4 of the runners at the end of the race was $5.65 \pm 1.42 \mathrm{mmol} . \Gamma^{-1}$ (mean \pm SD) and the estimated energy expenditure for the group was 6.22 M.J. While there was only a poor correlation between total energy expenditure and performance time for the race, the correlation coefficient was improved when the energy expenditure of each individual was expressed in KJ.kg-1 $\mathrm{min}^{-1}(r=-0.938 ; \mathrm{p}<0.01)$.
\end{abstract}

Key words: Running, Endurance, $\mathrm{VO}_{2}$ max, Lactate.

\section{INTRODUCTION}

The physiological characteristics of successful endurance athletes have been extensively studied and well documented (Milvey, 1977). These athletes have a characteristically large capacity for both oxygen transport and oxygen utilisation as reflected by their high maximum oxygen uptake $\left(\mathrm{VO}_{2}\right.$ max) values (Hermansen, 1973). A high $\mathrm{VO}_{2}$ max value is a necessary pre-requisite for high speed running because the oxygen cost of running is directly proportional to running speed. The ability to utilise a large proportion of $\mathrm{VO}_{2} \max$, for prolonged

\section{Correspondence to:}

Dr. Clyde Williams,

Department of Physical Education and Sports Science, University of Technology,

Loughborough,

Leics. LE11 3TU. periods of time, is also a characteristic of the well trained endurance athlete. During, for example marathon races the successful athletes appear to be able to utilise between $75-85 \%$ of their maximum aerobic capacities for the duration of the race (Costill and Fox, 1969; Costill, 1979; Davies and Thompson, 1979; Wells et al, 1981). The $\% \mathrm{VO}_{2} \max$ that an individual can sustain for a prolonged period of time is largely dependent on the capacity of working muscles to cover their energy needs by aerobic metabolism. When the exercise intensity is such that anaerobic metabolism has to compliment the aerobic production of energy, endurance capacity is reduced because of the increased rate of utilisation of the limited muscle glycogen stores (Karlsson and Saltin, 1971; Williams, 1982).

As a consequence of the extensive study of the physiological characteristics of successful endurance athletes, a strong association has evolved between $\mathrm{VO}_{2} \max$ and endurance capacity. This association has been such that 
$\mathrm{VO}_{2}$ max alone has been used as an indicator of endurance capacity in particular, and fitness in general (Åstrand and Rodahl, 1977; Cooper, 1968; Shepherd et al, 1968). There is however evidence to suggest that $\mathrm{VO}_{2}$ max per se is largely genetically predetermined (Komi and Karlsson, 1979) and that training-induced increases in endurance capacity are independent of $\mathrm{VO}_{2}$ max (Williams, 1981; Bland and Williams, 1982). Furthermore the recent popular interest and participation in long distance running has attracted individuals with modest $\mathrm{VO}_{2} \max$ values, who as a result of training, have developed the endurance capacity to complete marathon races. Therefore the purpose of the present study was to examine the relationships between the physiological characteristics of a group of recreational runners and their performance times in a halfmarathon race.

\section{METHODS}

The ten individuals, eight men and two women, who volunteered for this study were recreational runners who had taken part in a number of previous studies and who were, therefore, very familiar with the laboratory procedures employed in this investigation. All of the subjects had been running for at least a year, covering on average between 90 and $180 \mathrm{~km}$ a week in training. One of the women and four of the men had trained for and completed a marathon in the year prior to this study, their times being 4 hours, 3.25 hours, 3.33 hours, 3.56 hours for the woman and the three men respectively.

The half-marathon distance $(22.1 \mathrm{~km})$ was made up of a 4 lap course around the campus of Loughborough University. The first half of each lap was run on roads, closed off to traffic, while the second half of each lap was run on playing fields. There were two short $(200 \mathrm{~m})$ steep hills which were approximately $2 \mathrm{~km}$ apart, one was on the road section and the other was on the grass section of the course. Drinking water was available at two points on the $5 \mathrm{~km}$ lap course and they were separated by approximately $2.5 \mathrm{~km}$. The race began at 1.30 hours on a warm overcast June day $\left(14^{\circ} \mathrm{C} 67 \%\right.$ humidity) and all but 2 of the 200 runners completed the full distance. The race was won by a club athlete who covered the 4 lap course in 68 minutes.

Four of the group of recreational runners in this study agreed to give blood samples during each lap of the race. Capillary blood samples were obtained from each runner's thumb at the start of the race and then again at the end of each of the four laps; blood sampling was carried out at the road side and took only 30 seconds per person per lap. The maximum oxygen uptake of each of the 10 runners was determined during the week before or during the week after the race using the Taylor Treadmill Test. The treadmill running speed was $188 \mathrm{~m} \cdot \mathrm{min}^{-1}$ for the women and $215 \mathrm{~m} \cdot \mathrm{min}^{-1}$ for the men (Taylor et al, 1955). In addition each subject underwent, on a separate day, a submaximal running test on a level treadmill. This test involved continuous running for 4 minutes at 4 different speeds which were chosen so as to demand 60 to $95 \%$ of each individual's $\mathrm{VO}_{2}$ max. Blood samples were obtained every 4 minutes from the thumb of each subject without interrupting their running; each of the duplicate $25 \mu \mathrm{l}$ blood samples was deproteinised in $250 \mu$ l of $2.5 \%$ perchloric acid, centrifuged, frozen and then stored at $-20^{\circ} \mathrm{C}$. During the $\mathrm{VO}_{2}$ max test expired air samples were collected during the last minute of each 3 minute period whereas during the level running test expired air samples were collected during the last minute of each 4 minute period. The subject breathed through a low resistance respiratory valve (Jakeman and Davies, 1979) and lightweight wide-bore tubing $(30 \mathrm{~cm})$ into 150 litre capacity Douglas bags. The heart-rates of each subject as well as ECG profiles were monitored during treadinill running using chest electrodes and a Camtrace oscilloscope (Cambridge Instruments Ltd.).

\section{ANALYSES}

The percentages of oxygen and carbon dioxide in each expired air sample were determined using a paramagnetic oxygen analyser (Sybron-Taylor Ltd., Model 570A) and an infra-red carbon dioxide analyser (Mines Safety Appliance Ltd. Lira Model 303). Both analysers were calibrated before and during each series of analyses with nitrogen, a calibration gas and room air. The volume of each expired air sample was determined by evacuating the contents of each Douglas bag through a dry gas meter (Parkinson-Cowan Ltd.) previously calibrated with 600 litre Tissot spirometer (Collins Ltd., USA). The reproducibility of the methods for the collection and analysis of expired air samples was examined with one runner who performed the submaximal running test on 5 consecutive days. The coefficient of variation for each of the following speeds 161, 188, 214.5 and 241 m.min ${ }^{-1}$ was $3.5 \%, 2.5 \%, 2.0 \%$ and $1.0 \%$ respectively.

Blood samples obtained during the race and during the treadmill test were analysed for lactic acid using a modification of Olsen's fluorimetric procedure in which $25 \mu \mathrm{l}$ of supernant and $250 \mu \mathrm{l}$ of reaction mixture was used per analysis (Olsen, 1971). The coefficient of variation of this analytical procedure was $3.0 \%$ when determined for blood samples taken during exercise. Regression equations were calculated for the relationship between the oxygen consumption and running speed for each individual. Individual regression equations were then used to estimate the oxygen cost of running at race pace. The speeds equivalent to blood lactate concentrations of $4 \mathrm{mmol} . \Gamma^{1}(V 4 \mathrm{mM})$ were derived from the relationship between blood lactate concentrations and running speeds for 9 of the 10 subjects. 


\section{RESULTS}

The ages, heights and weights of the ten subjects are shown in Table $I$ along with the results of the maximum oxygen uptake tests. The mean $\mathrm{VO}_{2}$ max value for the group was $58.1 \pm 5.5 \mathrm{ml}^{\circ} \mathrm{kg}^{-1} \mathrm{~min}^{-1}$ (mean \pm SD) whereas the values for the eight men and two women in the group were $59.9 \pm 4.6$ and $50.9 \pm 0.3 \mathrm{ml}^{. k g^{-1}} \mathrm{~min}^{-1}$ respectively. Maximum ventilation rates for the women were lower than the values for the men but there were no differences between their maximum heart-rates (Table 1). The oxygen cost of submaximal treadmill running over a range of speeds is shown in Figure 1; the regression equation describing this relationship is $Y=$ $0.200 x+1.19$ (where $X$ represents running speed in m. $\min ^{-1}$ ). The two women did not run at the highest speed shown in Figure 1 because the oxygen demands of this speed were in excess of their $\mathrm{VO}_{2}$ max. The race times for the half-marathon along with the estimated oxygen cost and estimated \% $\mathrm{VO}_{2}$ max utilised by the runners during the race are shown in Table II. The mean value for the 10 runners for the percentage of $\mathrm{VO}_{2}$ max used during the race was $79 \%$ with values ranging

\section{TABLE I}

Physiological characteristics of the recreational runners

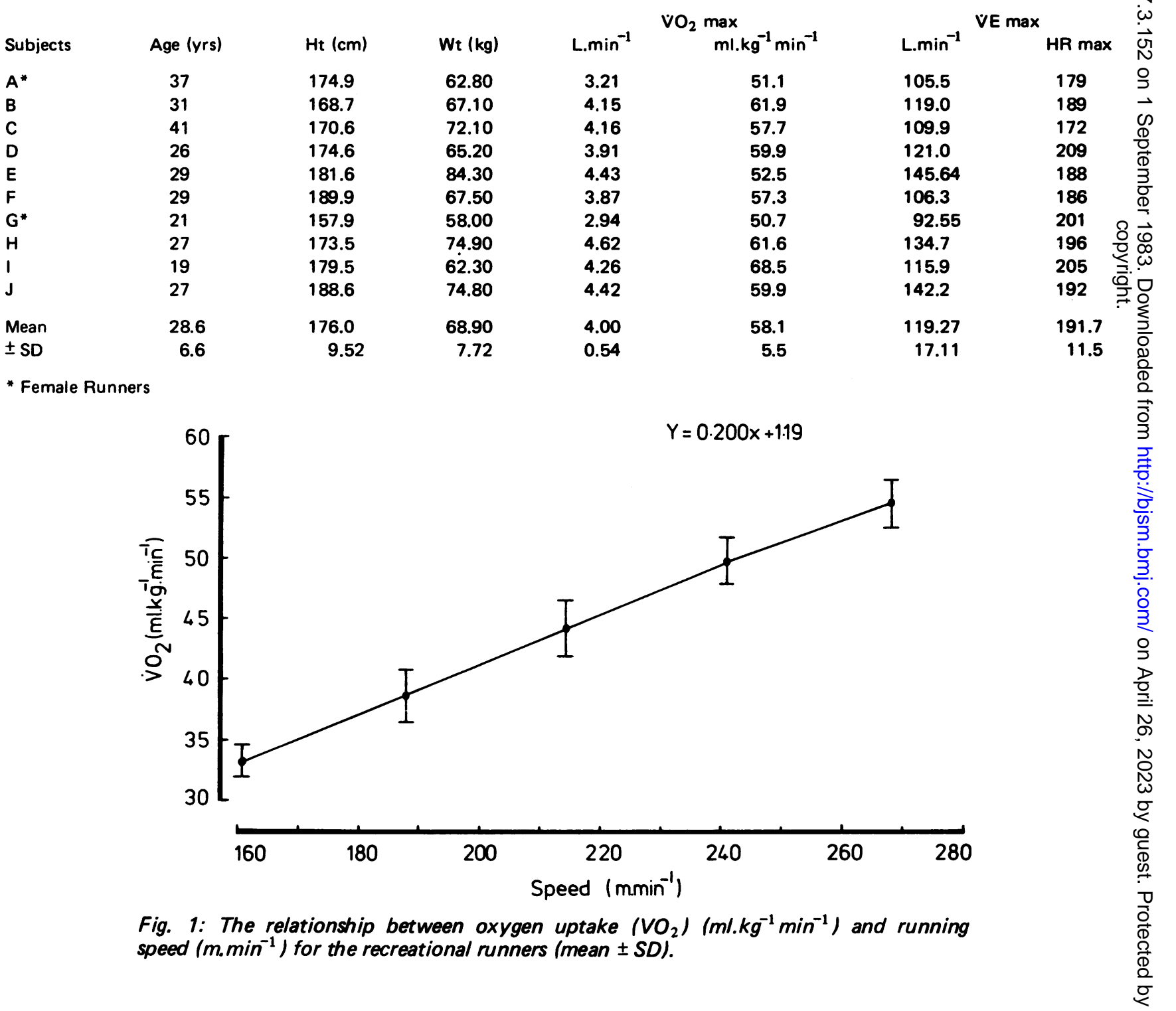


TABLE II

The maximum oxygen uptake $\left(\mathrm{VO}_{2}\right.$ max), running time, race pace, estimated oxygen consumption $\left(E s t . \mathrm{VO}_{2}\right)$ and estimated $\% \mathrm{VO}_{2} \max$ for the recreational runners.

\begin{tabular}{|c|c|c|c|c|c|}
\hline \multirow[b]{2}{*}{ Subjects } & \multicolumn{5}{|c|}{ Half-Marathon } \\
\hline & $\left.\underset{\left(m l . \mathrm{kg}^{-1}\right.}{\mathrm{VO}_{2}} \max ^{-1}\right)$ & $\begin{array}{c}\text { Time } \\
\text { (hr:min) }\end{array}$ & $\begin{array}{l}\text { Race Pace } \\
\left(\mathrm{m} \cdot \mathrm{min}^{-1}\right)\end{array}$ & $\begin{array}{c}\text { Est. } \mathrm{VO}_{2} \\
\left(\mathrm{ml}^{-1} \mathrm{~kg}^{-1} \mathrm{~min}^{-1}\right)\end{array}$ & Est. $\% \underset{\%}{\mathrm{VO}_{2}} \max$ \\
\hline$A *$ & 51.1 & $1: 41: 00$ & 208.9 & 41.3 & 81 \\
\hline B & 61.9 & $1: 29: 30$ & 235.8 & 47.1 & 76 \\
\hline C & 57.7 & $1: 32: 25$ & 228.2 & 47.1 & 82 \\
\hline D & 59.9 & $1: 35: 00$ & 222.1 & 47.8 & 80 \\
\hline $\mathbf{E}$ & 52.5 & $1: 47: 02$ & 197.1 & 40.0 & 76 \\
\hline $\mathbf{F}$ & 57.3 & $1: 48: 00$ & 195.3 & 39.7 & 69 \\
\hline G* & 50.7 & $1: 47: 02$ & 197.1 & 42.0 & 83 \\
\hline H & 61.6 & $1: 28: 05$ & 293.5 & 51.9 & 84 \\
\hline 1 & 68.5 & $1: 23: 40$ & 252.1 & 52.0 & 76 \\
\hline $\mathbf{J}$ & 59.9 & $1: 22: 47$ & 254.8 & 49.5 & 83 \\
\hline Mean & 58.1 & $1: 35: 27$ & 223.1 & 45.8 & 79 \\
\hline $\pm S D$ & 5.5 & $0: 9: 45$ & 22.7 & 4.7 & 5 \\
\hline
\end{tabular}

* Female Runners

from $69 \%$ to $84 \% \mathrm{VO}_{2}$ max. Seven of the ten subjects (one woman and 6 men) ran a second half-marathon race on a very warm overcast day $\left(23^{\circ} \mathrm{C} ; 76 \%\right.$ humidity). approximately 8 weeks after the race reported in the present study. The results of the first and the second half-marathon races are shown in Table III for the purpose of comparison. In the second half-marathon race the mean value for the estimated percentage of $\mathrm{VO}_{2}$ max used was $77 \pm 5 \% \mathrm{VO}_{2} \max$. There was no significant difference between the performance times nor between the $\% \mathrm{VO}_{2} \max$ utilised by the subjects during the two half-marathon races.

\section{TABLE III}

Performance times and estimated $\% \mathrm{VO}_{2} \max$ for 7 recreational runners during two half-marathon races.

\begin{tabular}{|c|c|c|c|c|}
\hline \multirow{2}{*}{ Subjects } & \multicolumn{2}{|c|}{ 1st Half-Marathon (13.6.82) } & \multicolumn{2}{|c|}{ 2nd Half-Marathon (8.8.82 } \\
\hline & Time & Est. $\% \mathrm{VO}_{2} \max$ & Time & Est. $\% \mathrm{VO}_{2} \max$ \\
\hline$A^{*}$ & $1: 41: 00$ & 81 & $1: 46: 00$ & 77 \\
\hline B & $1: 29: 30$ & 76 & $1: 27: 15$ & 78 \\
\hline C & $1: 32: 25$ & 82 & $1: 35: 00$ & 79 \\
\hline D & $1: 35: 00$ & 80 & $1: 42: 00$ & 75 \\
\hline $\mathbf{E}$ & $1: 47: 02$ & 76 & 2:00:00 & 68 \\
\hline $\mathbf{F}$ & $1: 48: 00$ & 69 & $1: 41: 00$ & 75 \\
\hline H & $1: 28: 05$ & 84 & $1: 27: 15$ & 85 \\
\hline ean & $1: 37: 17$ & 79 & $1: 39: 47$ & 77 \\
\hline \pm SD & $8: 90$ & \pm 5 & $11: 29$ & \pm 5 \\
\hline
\end{tabular}

* Female Runner
The blood lactic acid concentrations of the four subjects for each of the 4 laps are shown in Table IV. Each of these four subjects appeared to be able to maintain a consistent average speed as reflected by their times for the 4 laps of the course (Table IV). Figure 2 shows the relationship between blood lactate concentration and running speed for subject $I$ and also the derivation of the speed equivalent to $4 \mathrm{mmol}^{-\Gamma^{1}}$ (V) $4 \mathrm{mM}$ ) for this subject. In Figure 3 the changes in blood lactate concentrations, over a range of running speeds, are shown for the four subjects from whom blood samples were obtained during the race, and in Figure 4 the running speeds have been expressed in terms of the $\% \mathrm{VO}_{2} \max$ utilised at each speed. The running speeds equivalent to a blood lactate concentration of 4 mmol. $\Gamma^{1}(\mathrm{~V} 4 \mathrm{mM})$ and the $\% \mathrm{VO}_{2} \max$ that these speeds represent are shown in Table IV along with the relationship between racing speed and $V(4 \mathrm{mM})$. Whereas the $\% \mathrm{VO}_{2}$ max utilised during the race was $78 \%$ for 9 of the runners, the speed equivalent to $\mathrm{V}(4 \mathrm{mM})$ represented $84 \% \mathrm{VO}_{2}$ max. There was a good correlation between each individuals racing speed and their running speed at $V(4 \mathrm{mM})(r=0.89 ; p<0.01)$.

The energy expenditure of the group during the halfmarathon race was estimated from the respiratory exchange ratio ( $R$ ) and the oxygen cost of treadmill running at race pace (Table $V$ ) and was found to be 6.27 M.J., with a range of individual values between 5.47 M.J. and 7.61 M.J. The lowest total energy expenditure was 5.47 M.J. was achieved by one of the women, subject A (Table II). In contrast, the largest total energy expenditure was achieved by one of the men, subject E (7.61 M.J.) who had a slower running 
TABLE IV

Time per lap, lap speed and blood lactate concentrations $\left(\mathrm{mmol} . \Gamma^{-1}\right)$ for 4 of the 10 runners.

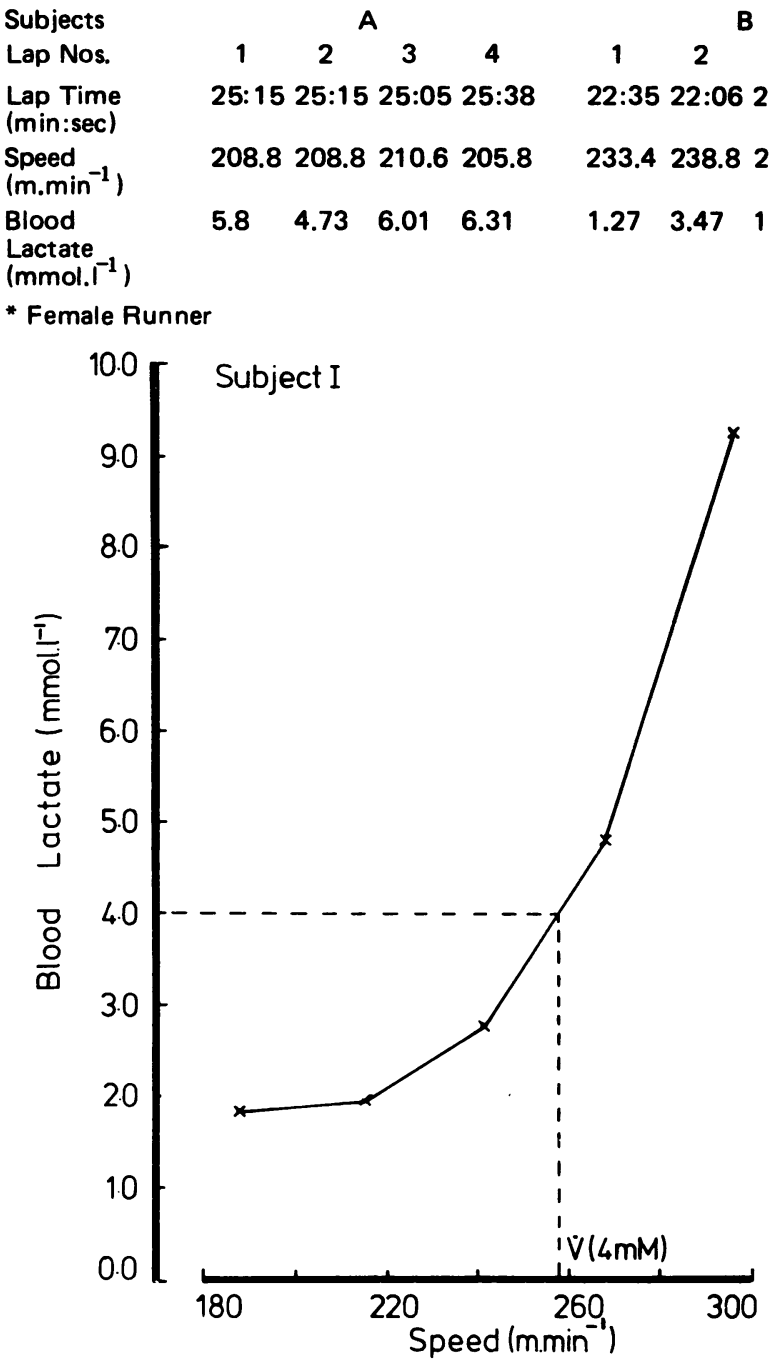

Fig. 2: The relationship between running speed (m. min $^{-1}$ ) and blood lactate concentrations (mmol. $\Gamma^{-1}$ ) for one of the recreatonal runners. The broken line shows the identification of the running speed equivalent to $4 \mathrm{mmol} . \Gamma^{1}$ for this subject.

time than the majority of the men in the group. There was a poor correlation between performance times and the total energy expenditure for the race $(r=-0.02)$, but a good correlation ( $r=0.94 ; p<0.01)$ between performance times and the rate of energy expenditure per minute per unit body weight i.e. $\mathrm{KJ}_{\mathrm{kg}} \mathrm{g} \mathrm{min}^{-1}$

\section{DISCUSSION}

The mean $\mathrm{VO}_{2}$ max value for the men in the group was $59.9 \mathrm{ml} . \mathrm{kg}^{-1} \mathrm{~min}^{-1}$ and for the women the value was

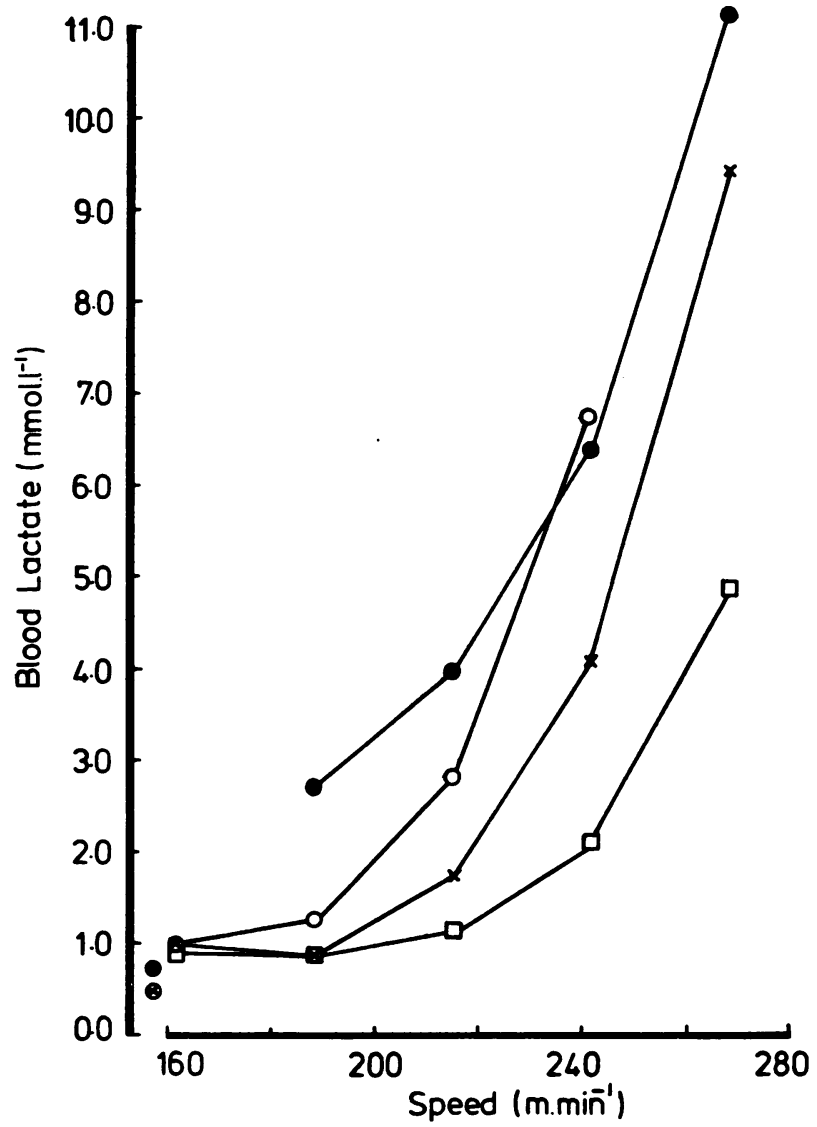

Fig. 3: The relationship between running speed ( $\mathrm{m}^{\mathrm{min}} \mathrm{m}^{-1}$ ) and blood lactate concentrations (mmol. $\Gamma^{-1}$ ) for the four runners from whom blood samples were also obtained during the race. (The values for the subjects, $A, B, C$ and $D$ are represented by the symbols $\mathrm{O}, \mathrm{Q}, \mathrm{X}$ and $\bullet$ respectively).

$50.9 \mathrm{ml} . \mathrm{kg}^{-1} \mathrm{~min}^{-1}$. These values are similar to those which have been obtained for active male and female physical education students while performing the same test procedures (Williams, 1981). However these $\mathrm{VO}_{2}$ max values do not approach the high values of 70-80 


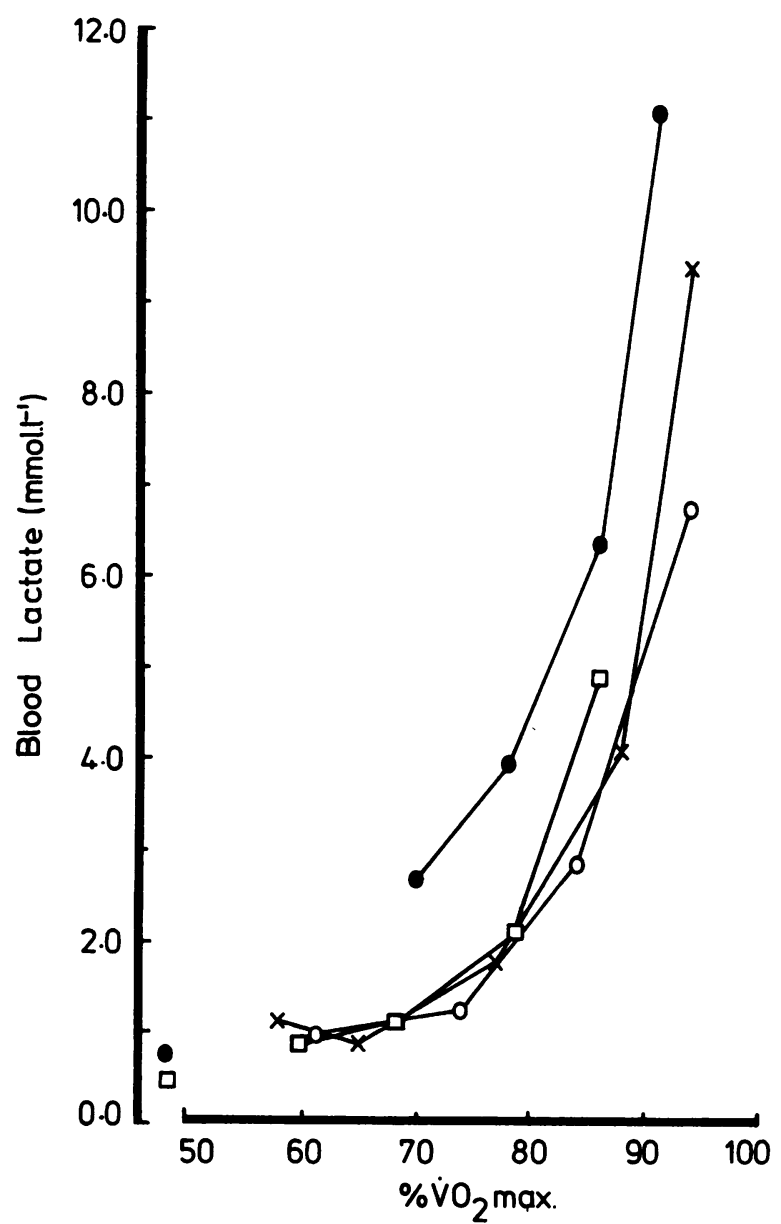

Fig. 4: The relationship between blood lactate concentrations (mmol. $\left.\Gamma^{-1}\right)$ and running speeds expressed as $\% \mathrm{VO}_{2}$ max for each of the four individuals from whom blood samples were also obtained during the race (symbols are the same as shown in Fig. 3).

$\mathrm{ml} . \mathrm{kg}^{-1} \mathrm{~min}^{-1}$ reported for elite endurance athletes (Åstrand and Rodahl, 1977; Costill, 1979; Davies and Thompson, 1979). Neither did the performance times of these subjects approach the times expected from elite or nationally ranked distance runners. The winner's time for this race was 68 minutes, which was 15 minutes faster than the finishing time of the fastest of the recreational runners. Estimating the oxygen cost of the winners average race pace of $310.8 \mathrm{~m} \cdot \mathrm{min}^{-1}$ (or 5.2 $\mathrm{min} / \mathrm{mile}$ ) from the regression equation $Y=0.200 \times$

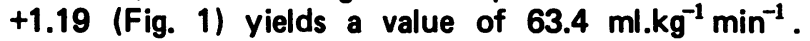
Assuming that this individual was using between $80 \%$ and $85 \%$ of his $\mathrm{VO}_{2} \max$ (Davies and Thompson, 1979) then his $\mathrm{VO}_{2} \max$ would have been in the range 75-79 ml. $\mathrm{kg}^{-1} \mathrm{~min}^{-1}$ which is over $10 \mathrm{ml} . \mathrm{kg}^{-1} \mathrm{~min}^{-1}$ greater than the highest value recorded for the recreational runners.

\section{TABLE V}

Average running speeds during the race (V Race) and the estimated $\% \mathrm{VO}_{2}$ max plus the running speeds equivalent to a blood lactate concentration of $4 \mathrm{mmol} . \Gamma^{-1}$ $(V(4 \mathrm{mM}))$ and the estimated $\% \mathrm{VO}_{2} \max$ for $\mathrm{V}(4 \mathrm{mM})$ $(n=9)$.

\begin{tabular}{|c|c|c|c|c|}
\hline \multirow[b]{2}{*}{ Subjects } & \multicolumn{2}{|c|}{ V Race } & \multicolumn{2}{|c|}{$V(4 \mathrm{mM})$} \\
\hline & $V m \cdot \min ^{-1}$ & $\% \mathrm{VO}_{2} \max$ & Vm. $\min ^{-1}$ & $\% \mathrm{VO}_{2} \max$ \\
\hline$A^{*}$ & 208.9 & 81 & 222.6 & 87 \\
\hline B & 235.8 & 76 & 259.3 & 84 \\
\hline C & 228.2 & 82 & 239.5 & 88 \\
\hline D & 222.1 & 80 & 214.5 & 78 \\
\hline E & 197.1 & 76 & 219.1 & 85 \\
\hline $\mathbf{F}$ & 195.3 & 69 & 221.8 & 79 \\
\hline $\mathbf{G}^{*}$ & 197.1 & 83 & 214.5 & 90 \\
\hline 1 & 252.1 & 76 & 257.4 & 77 \\
\hline $\mathbf{J}$ & 254.8 & 83 & 269.1 & 87 \\
\hline Mean & 221.3 & 78 & 235.3 & 84 \\
\hline $\pm S D$ & 23.3 & 5 & 21.5 & 5 \\
\hline
\end{tabular}

\section{TABLE VI}

Estimated energy expenditure during the half-marathon race $(n=10)$.

\begin{tabular}{|c|c|c|c|c|}
\hline ariable & Mean & $\pm S D$ & Min & Max \\
\hline 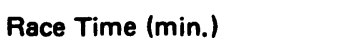 & 95.45 & 9.75 & 82.78 & 107.03 \\
\hline lue & 0.98 & 0.03 & 0.93 & 1.0 \\
\hline Est. $\mathrm{VO}_{2}\left(\right.$ L. $\left.\mathrm{min}^{-1}\right)$ & 3.16 & 0.47 & 2.68 & 3.89 \\
\hline Est. Energy Exp. (K. & 66.3 & 10.1 & 51.5 & 82.1 \\
\hline st. Total Energy Exp. & 6.27 & 0.72 & 5.47 & 7.61 \\
\hline
\end{tabular}

The recreational runners in the present study were able to utilise an estimated $79 \%$ of their maximum aerobic capacities during the race. These results are similar to those values for endurance athletes reported by other authors (Costill, 1979; Davies and Thompson, 1979). Although this information about the $\% \mathrm{VO}_{2}$ max utilised during a race is derived from the results of laboratory treadmill running, there does appear to be a good correlation between the oxygen cost of treadmill running and track running over the range of speeds observed in this study (McMiken and Daniels, 1976). However when the race is run over varying terrain it is difficult to select a section of the course along which a representative sample of the oxygen consumption of the runners could be determined. Costill, Gollnick and co-workers (1973a) determined the oxygen cost of running at race pace on a treadmill and during various sections of a hilly cross-country course for a group of experienced endurance runners. They reported that 
laboratory treadmill running at race pace demanded $71 \% \mathrm{VO}_{2} \max \left(65 \%-78 \% \mathrm{VO}_{2} \max \right)$ whereas during a flat part of the course, a downhill section and an uphill section, the runners utilised an average of $83 \% \mathrm{VO}_{2}$ $\max , 76 \% \mathrm{VO}_{2} \max$ and $90 \% \mathrm{VO}_{2}$ max respectively. Thus the underestimation of the $\% \mathrm{VO}_{2} \max$ utilised was probably due to the hilly nature of the course which was physiologically more demanding than was reflected by the average running speed for the race. In the present study the estimated $\% \mathrm{VO}_{2}$ max utilised by the subjects did not include a correction for wind resistance and while the performance times have been presented as average speeds or race pace, it is fully appreciated that running speed varies with the terrain. Furthermore a runner will vary his pace frequently, for short periods of time, in an attempt to maintain the highest speed while not exceeding a tolerable level of discomfort. The relative contributions of the various physiological signals to the feelings of tolerable or intolerable physical discomfort during exercise have yet to be clearly identified (Borg, 1973).

The oxygen cost of treadmill running over a range of speeds, which included the speeds at which the halfmarathon was run, was $200 \mathrm{ml} . \mathrm{kg}^{-1} \mathrm{~min}^{-1}$, which is similar to the values reported by other authors (Margaria, 1963; Daniels and Oldridge, 1970; Åstrand and Rodahl, 1977). There was little individual variation in the oxygen cost of running at different speeds, for example at $241.0 \mathrm{~m} \cdot \mathrm{min}^{-1}(14.45 \mathrm{KPH})$ the values ranged from $47.2 \mathrm{ml}_{\mathrm{kg}}^{-1} \mathrm{~min}^{-1}$ to $52.6 \mathrm{ml} . \mathrm{kg}^{-1} \mathrm{~min}^{-1}$

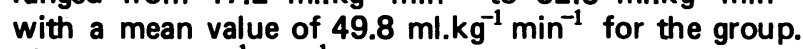
This $5.5 \mathrm{ml} . \mathrm{kg}^{-1} \mathrm{~min}^{-1}$ range of values for the oxygen cost of running at the same speed is relatively small in comparison with the $15 \mathrm{ml}^{.} \mathrm{kg}^{-1} \mathrm{~min}^{-1}$ range of values reported by Sjodin and Schele (1982) for endurance athletes running at $15 \mathrm{KPH}$. These authors reported a good correlation $(r=0.75 ; p<0.05)$ between the oxygen cost of running at $15 \mathrm{KPH}$ and performance times for $5000 \mathrm{~m}$ races. No similar relationship between "running economy" (i.e. oxygen cost of running at a fixed speed) and performance time in the half-marathon race was found in the present study. The correlation coefficient for the oxygen cost of running at $14.45 \mathrm{KPH}$ and the performance time for the half marathon was $r=0.24$ (N.S.). A better correlation was found between the $\mathrm{VO}_{2}$ max values of the recreational runners and their half-marathon performance times $(r=-0.81 ; p<0.01)$. Similar good correlations between $\mathrm{VO}_{2}$ max and running performance have been reported by other authors (Karlsson and Saltin, 1971; Costill et al, 1973b; Foster et al, 1978; Davies and Thompson, 1979). However this relationship only holds true for a group of subjects for whom there is a range of $\mathrm{VO}_{2}$ max values. This is because sustained high speed running requires a large oxygen consumption and so individuals with high $\mathrm{VO}_{2}$ max values are able to run faster than those individuals with low $\mathrm{VO}_{2}$ max values. Thus differences in $\mathrm{VO}_{2}$ max values can explain the differences in the running performances of a group of individuals within which there is a large range of $\mathrm{VO}_{2} \max$ values.

While a high $\mathrm{VO}_{2}$ max value is necessary for high speed running, individuals with the same or similar $\mathrm{VO}_{2}$ max values may have different performance times. These differences in performance times cannot be readily explained by the different $\% \mathrm{VO}_{2}$ max utilised by the runners during the race because there was only a poor correlation between these two variables $(r=$ -0.357, N.S.). In the present study the subjects $D$ and J had the same $\mathrm{VO}_{2}$ max values and yet completed the half-marathon in 1:35:0 and 1:22:47 respectively, i.e. a difference of 12 minutes or approximately 2 miles. In contrast the subjects $I$ and $J$ had the fastest times for the group (i.e. 1:23:40 and 1:22:47) and yet their $\mathrm{VO}_{2}$ max values were quite different (68.5 and 59.9 ml. $\mathrm{kg}^{-1} \mathrm{~min}^{-1}$ ) (Table II). It has been suggested that the differences in the performances of endurance athletes with similar $\mathrm{VO}_{2}$ max values are best explained by the differences in their running economy (Conley and Krahenbuhl, 1980). There were no obvious differences in the oxygen cost of running at the same treadmill speed for the subjects $D, J$ and $I$ and so differences in running economy do not readily explain the differences in their performance times.

The running speeds at which blood lactic acid concentration increase above resting values have also been? shown to have a better correlation with endurance performance than does $\mathrm{VO}_{2}$ max alone (Farrell et al, 1979; Sjodin and Jacobs, 1981; Kumagai et al, 1982). An increase in blood lactate concentration reflects an increased rate of glycogenolysis in working muscles and that the exercise intensity demands a contribution to aerobic metabolism from the anaerobic degradation of muscle glycogen. The exercise intensity at which the blood lactic acid concentration increases above preexercise values has been termed the "anaerobic threshold" by some authors (Wasserman et al, 1973; Davis et al, 1976) and by other authors it has been called the "aerobic threshold" (Kinderman et al, 1979; Skinner and McLellan, 1980). Kinderman and co-workers have suggested that exercise intensities equivalent to a blood lactate concentration of $2 \mathrm{mmol} . \Gamma^{1}$ and $4 \mathrm{mmol} . \Gamma^{1}$. should be called the "aerobic and anaerobic" thresholds respectively (Kinderman et al, 1979). The rationale for the use of these two reference points is that a blood lactic acid concentration of $2 \mathrm{mmol} . \Gamma^{-1}$ represents the early increase in the accumulation of lactate above preexercise levels whereas $4 \mathrm{mmol} . \Gamma^{1}$ is close to the exercise intensity above which there is a rapid increase in blood lactate concentrations (Fig. 2). Sjodin and Jacobs (1981) have called running speeds equivalent to a blood lactate concentration of $4 \mathrm{mmol} . \Gamma^{1}$ the "onset of blood lactate accumulation (OBLA)" and a good correlation was found between running speeds equivalent to OBLA 
and marathon performance times of experienced runners $(r=0.96 ; p<0.001)$. However these authors did not report the correlation coefficient for the relationship between the performance times and the $\mathrm{VO}_{2}$ max values for their subjects. The performance times for the 18 runners ranged from 2:22:10 to 4:12:12 suggesting that, with such a heterogeneous group, the correlation coefficient for the relationship between performance times and $\mathrm{VO}_{2} \max$ values would have been at least as good as the value reported in the present study.

The correlation coefficient for the relationship between performance times in the half-marathon race and the treadmill speeds equivalent to a blood lactate concentration of $4 \mathrm{mmol} . \Gamma^{-1}$ i.e. V(4mM) or OBLA, was $-0.877(p<0.01)$. Therefore $77 \%$ of the variation in individual performances may be associated with the ability to run at high speeds with low blood lactate concentrations, whereas differences in $\mathrm{VO}_{2}$ max may account for only $65 \%$ (i.e. $r=-0.81$ ) of the variation in individual performance times. These results are similar to those recently reported for the relationships between anaerobic thresholds of young endurance athletes and their performance times in races of $5 \mathrm{~km}, 10 \mathrm{~km}$ and $16.09 \mathrm{~km}$ (Kumagai et al, 1982). Thus the different performance times of individuals with the same $\mathrm{VO}_{2}$ max values may be partly explained in terms of their different $V(4 \mathrm{mM})$ values. For example the two subjects $D$ and $J$ with the same $V_{2}$ max values had $V(4 \mathrm{mM})$ values which were quite different in that $V(4 \mathrm{mM})$ for subject $D$ was $214.5 \mathrm{~m} \cdot \mathrm{min}^{-1}$ or $7.5 \mathrm{~min} / \mathrm{mile}$ pace whereas the $V(4 \mathrm{mM})$ for subject $J$ was $269.1 \mathrm{~m} \cdot \mathrm{min}^{-1}$ or $6.0 \mathrm{~min} / \mathrm{mile}$ pace. It is also of interest to note that the subject $\mathrm{J}$ who had a $\mathrm{VO}_{2} \max$ value of 59.9 $\mathrm{ml} . \mathrm{kg}^{-1} \mathrm{~min}^{-1}$ finished the race almost one minute ahead of subject I who had a $\mathrm{VO}_{2}$ max value of 68.5 $\mathrm{ml} . \mathrm{kg}^{-1} \mathrm{~min}^{-1}$. An examination of the $V(4 \mathrm{mM})$ values for these two subjects shows that subject $J$ had a value of $269.1 \mathrm{~m} \cdot \mathrm{min}^{-1}$ compared with a value of $257.4 \mathrm{~m} \cdot \mathrm{min}^{-1}$ for subject I. These results show that subject J, with the smaller $\mathrm{VO}_{2} \max$ value was able to run at speeds almost a half a minute per mile faster than subject I with the same blood lactate concentration. The fact that subject $\mathrm{J}$ was able to utilise an estimated $83 \%$ of his $\mathrm{VO}_{2}$ max whereas subject I was only using $76 \%$ of his $\mathrm{VO}_{2}$ max may be explained in terms of these differences in the $\% \mathrm{VO}_{2}$ max at which there is a significant increase in muscle lactate and hence blood lactate concentrations. Therefore the assessment of an individual's endurance capacity may be best achieved by describing the $\% \mathrm{VO}_{2} \max$ at which that individual is able to exercise without a significant increase in blood lactate concentration. The use of reference concentrations of blood lactate e.g. $2 \mathrm{mmol} . \Gamma^{1}$ and or $4 \mathrm{mmol} . \Gamma^{1}$ however, offers a more practical solution to the problem of determining at which point there is a significant increase in blood lactate concentrations because it requires less blood sampling.
At the end of the half-marathon the blood lactate concentration of the four subjects was $5.65 \pm 1.42$ mmol. $\Gamma^{1}$ (mean \pm SD) which was similar to the values reported for experienced male and female endurance runners covering approximately the same distances (Costill, Gollnick et al, 1973a; Haralambie et al, 1981). As might be expected the blood lactate concentrations of the subjects at the end of the half-marathon race were less than those reported for subjects at the end of a 16 $\mathrm{km}$ race $\left(7.72 \pm 1.42 \mathrm{mmol} . \mathrm{\Gamma}^{1}\right.$ ) (Costill, Thomason et al, $1973 \mathrm{~b})$ and greater than after a marathon (2.14 \pm 0.91 mmol. $\Gamma^{-1}$ ) (Costill and Fox, 1969; Costill, 1970). These differences in blood lactate concentrations reflect the differences in exercise intensity and the rates at which carbohydrate contributes to energy metabolism in these races.

The estimated energy expenditure for the group during the half-marathon race was 6.22 M.J. (range 5.12 M.J. to 7.61 M.J.) and it is about half the daily energy intake of active individuals (Wootton et al, 1981). The highest total energy expenditure was incurred not by the fastest runner but by one of the men who had one of the slowest speeds, and yet who had a large oxygen consumption due to his greater body weight. The speed at which he was running required a relatively low oxygen consumption when expressed per unit of body weight, however the larger the body weight, the larger the total oxygen consumption required to sustain even a slow running speed. While there was only a poor correlation between the performance time in the half-marathon and the total energy expenditure for the recreational runners, there was a good correlation between performance time and energy expenditure per minute, per unit body weight $(r=$ $0.936 ; p<0.01)$. This, of course, is derived from the estimated oxygen cost of running at race pace and so as expected, an equally good correlation exists between performance times of the group and estimated oxygen cost of running at race pace $(r=-0.938 ; p<0.01)$.

In conclusion the results of the present study suggest that while the $\mathrm{VO}_{2} \max$ values of these recreational runners were not as high as those of endurance athletes, they were able to utilise similar proportions of their $\mathrm{VO}_{2}$ max during the half-marathon race. The differences in their performance times could not be explained in terms of the differences in $\% \mathrm{VO}_{2}$ max used by each runner during the race. The performance times were however, more highly correlated with the running speeds at which blood lactate concentrations reached 4 mmol. $\Gamma^{1}$ than they were with $\mathrm{VO}_{2} \max$ per se.

\section{ACKNOWLEDGEMENTS}

Both Dr. C. Williams and this work are supported by The Sports Council. 


\section{REFERENCES}

Astrand, P. O. and Rodahl, K., 1977. A Textbook of Work Physiology. McGraw-Hill Book Co., New York.

Bland, P. and Williams, C., 1982 "Influence of training on maximum oxygen uptake and endurance capacity during single leg exercise". J.Physiol. (London) 32: 57P.

Borg, G. A. V., 1973 "Perceived exertion: a note on history and methods". Med.Sci.Sports 5: 90-93.

Conley, D. L. and Krahenbuhl, G. S., 1980 “Running economy and distance running performance of highly trained athletes". Med.Sci.Sports 12: 357-360.

Cooper, K. H., 1968 "Aerobics". Bantam Books, New York.

Costill, D. L. and Fox, E. L., 1969 “Energetics of marathon running”. Med.Scị.Sports 1: 81-86.

Costill, D. L., 1970 “Metabolic responses during distance running”. J.Appl.Physiol. 28: 251-255.

Costill, D. L., Gollnick, P. D., Jansson, E. D., Saltin, B. and Stein, E. M., 1973a “Glycogen depletion pattern in human muscle fibres during distance running". Acta physiol.scand. 89: 374-383.

Costill, D. L., Thomason, H. and Roberts, E., 1973b "Fractional utilisation of the aerobic capacity during distance running". Med.Sci.Sports 5: 248-252.

Costill, D. L., 1979 “A scientific approach to distance running". Track \& Field News, Los Altos, USA.

Daniels, J. T. and Oldridge, N., 1970 "The effects of alternate exposure to altitude and sea level on world class middle distance runners". Med.Sci.Sports 2: 107-112.

Davies, C. T. M. and Thompson, M. W., 1979 "Aerobic performance of female marathon and male ultramarathon athletes". Eurp.J.Appl.Physiol. 41: 233-245.

Davis, J. A., Vodak, P., Wilmore, J. H., Vodak, J. and Kurtz, P., 1976 "Anaerobic threshold and maximum aerobic power for three modes of exercise". J.Appl.Physiol. 41: 544-550.

Farrell, P. A., Wilmore, J. H., Coyle, E. F., Billing, J. E. and Costill, D. L., 1979 "Plasma lactate accumulation and distance running performance". Med.Sci.Sports 11: 338-344.

Foster, C., Costill, D. L., Daniels, J. T. and Fink, W. J., 1978 "Skeletal muscle enzyme activity, fibre composition and $\mathrm{VO}_{2}$ max in relation to distance running performance". Eur.J.Appl.Physiol. 39: 73-80.

Haralambie, G., Senser, L. and Sierra-Chavez, R., 1981 "Physiological and metabolic effects of a $25 \mathrm{~km}$ race in female athletes". Eur.J.Appl.Physiol. 47: 123-131.

Hermansen, L., 1973 “Oxygen transport during exercise in human subjects”. Acta physiol.scand.suppl. 399.

Jakeman, P. and Davies, B., 1979 "The characteristics of a low resistance breathing valve designed for the measurement of high aerobic capacity". Brit.J.Sports Med. 13: 81-83.

Karlsson, J. and Saltin, B., 1971 “Diet, muscle glycogen and endurance performance”. J.Appl.Physiol. 31: $203-206$.

Kindermann, W., Simon, G. and Keul, J., 1979 "The significance of the aerobic-anaerobic transition for the determination of work load intensities during endurance training". Eur.J.Appl.Physiol. 42: 25-34.

Komi, P. V. and Karlsson, J., 1979 "Physical performance, skeletal muscle enzyme activities and fibre types in monozygous and dizygous twins of both sexes". Acta physiol.scand.suppl. 462.

Kumagai, S., Tanaka, K., Matsuura, Y., Matsuzaka, A., Hirakoba, K. and Asano, K., 1982 "Relationships of the anaerobic threshold with $5 \mathrm{~km}, 10 \mathrm{~km}$ and 10 mile races". Eur.J.Appl.Physiol. 49: 13-23. 
Margaria, R., Cerretelli, P., Aghemo, P. and Sassi, G., 1963 "Energy cost of running". J.Appl.Physiol. 18: 367-370.

McMiken, D. F. and Daniels, J. T., 1976 "Aerobic requirements and maximum aerobic power in treadmill and track running". Med.Sci.Sports 8: 14-17.

Milvey, P., 1977 "The marathon: physiological, medical, epidemiological and psychological studies". Ann.N.Y.Acad. Sci. 301: 1-1099.

Olsen, C., 1971 "An enzymatic fluorimetric micromethod for the determination of acetoacetate, B-hydroxybutyrate, pyruvate and lactate". Clin.Chim.Acta 33: 293-300.

Shephard, R. J., Allen, C., Benade, A. J. S., Davies, C. T. M., Di Prampero, P. E., Hedman, R., Merriman, J. E., Myhre, K. and Simmons, R., 1968 "The maximal oxygen uptake. An international reference standard of cardio-respiratory fitness". Bull. WHO 38: 757-764.

Sjodin, B. and Jacobs, I., 1981 "Onset of blood lactate accumulation and marathon running performance". Int.J.Sports Med. 2: 23-26.

Sjodin, B. and Schele, R., 1982 "Oxygen cost of treadmill running". In: Exercise and Sport Biology (ed. P. V. Komi). Human Kinetics Publishers, Champaign, USA pp. 61-67.

Skinner, J. and McLellan, H., 1980 "The transition from aerobic to anaerobic metabolism". Res.Quart.Exercise Sport 51: 234-248.

Taylor, H. R., Buskirk, E. R. and Henschel, A., 1955 “Maximum oxygen intake as an objective measure of cardiorespiratory performance". J.Appl.Physiol. 8: 73-80.

Wasserman, K., Whipp, B. J., Koyie, S. N. and Beaver, W. L., 1973 "Anaerobic threshold and respiratory gas exchange during exercise". J.Appl.Physiol. 35: 236-243.

Wells, C. W., Hecht, L. H. and Krahenbuhl, G. S., 1981 "Physical characteristics and oxygen utilisation of male and female marathon runners". Res.Quart. Exercise and Sport 52: 281-285.

Williams, C., 1981 "The biological basis of aptitude: the endurance runner". J.Biosoc.Sci.Suppl. 7: 103-112.

Williams, C., 1982 "Dietary manipulation and athletic performance". In: Science and Sporting Performance: Management or Manipulation, (eds. B. Davies and G. P. Thomas) Oxford University Press, England pp. 6-22.

Wootton, S. A., Shorten, M. R. and Williams, C., 1981 "Nutritional manipulation of metabolism for the purpose of sport". In: Applied Nutrition 1, (ed. E. C. Bateman) Libby Press, London pp. 60-64. 